Document downloaded from:

http://hdl.handle.net/10251/70598

This paper must be cited as:

Macian Martinez, V.; B Tormos; Gomez Estrada, YA.; Salavert Fernández, JM. (2012).

Proposal of an FTIR Methodology to Monitor Oxidation Level in Used Engine Oils: Effects of Thermal Degradation and Fuel Dilution. Tribology Transactions. 55:872-882. doi:10.1080/10402004.2012.721921.

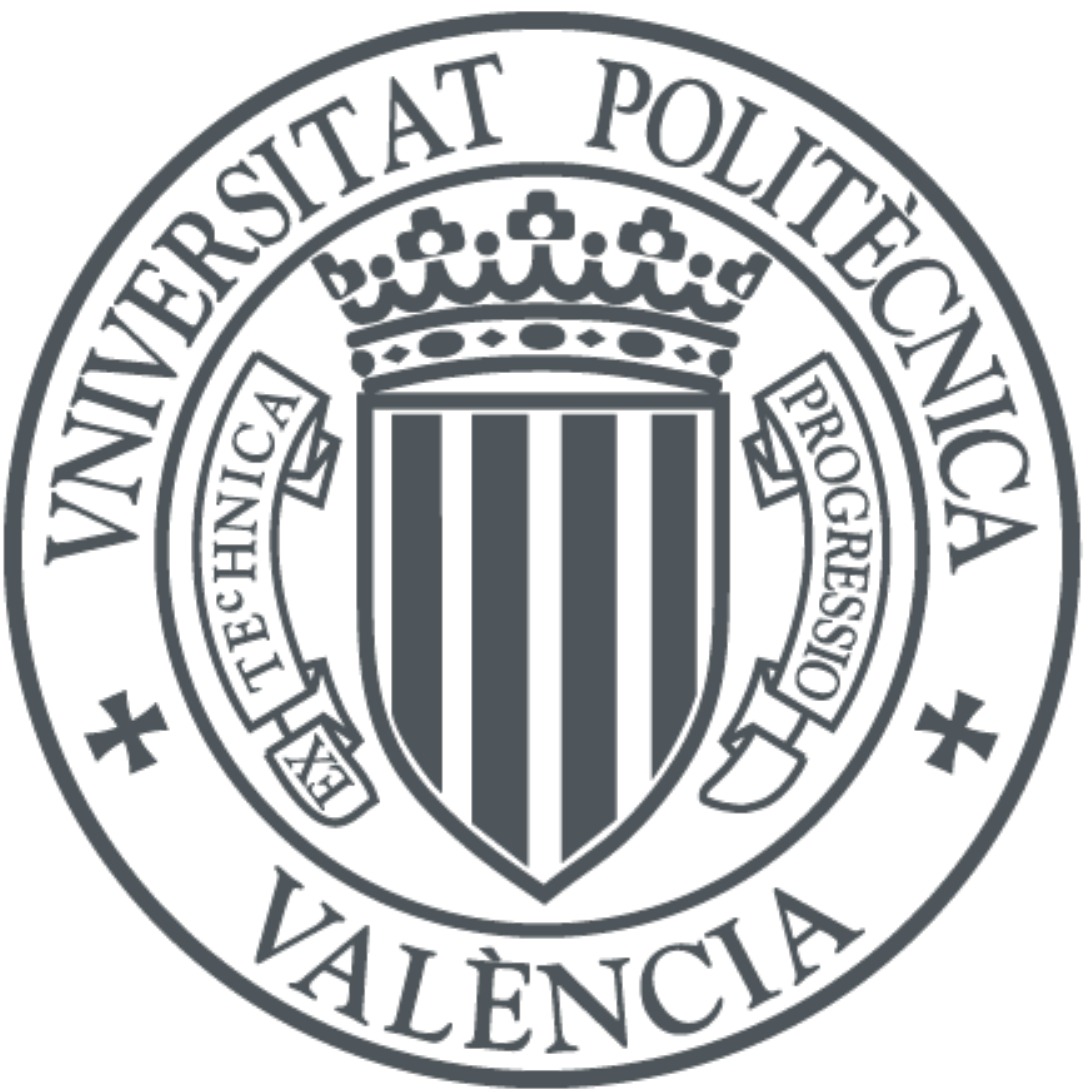

The final publication is available at

http://dx.doi.org/10.1080/10402004.2012.721921

Copyright Taylor \& Francis

Additional Information 


\title{
Proposal of a FT-IR methodology to monitor oxidation level in used engine oils: Effect of thermal degradation and fuel dilution
}

\author{
V. Macián, B. Tormos, Y.A. Gómez, J.M. Salavert \\ Universitat Politècnica de València, CMT-Motores Térmicos. Camino de Vera s/n. 46022, \\ Valencia, Spain
}

\begin{abstract}
This paper describes a particular procedure, based on ASTM D7214 and ASTM E 2412, which has been defined to improve oil oxidation quantification in used engine oils. Taking into account typical problems that can be found in this type of samples, thermal oxidation and fuel dilution, response on FT-IR spectra has been analyzed considering also the effect of oil formulation. Two special zones have been considered inside the typical wave number range for oxidation quantification, where those problems can be detected and assessed more easily. Zone A between $1,725 \mathrm{~cm}^{-1}$ and $1,650 \mathrm{~cm}^{-1}$, where products as aldehydes, carboxylic acids and ketones as main products of thermal degradation are identified, and Zone B between $1,770 \mathrm{~cm}^{-1}$ and 1,725 $\mathrm{cm}^{-1}$, where esters as main products for detection of fuel dilution problems when diesel engine is operating with biodiesel.
\end{abstract}

Keyword: Infra Red; Spectroscopy; Oil Condition Monitoring; Lubricant Degradation; Internal Combustion Engine Oils.

\section{Introduction}

Taking into account that oxidation is the most predominant reaction of a lubricant in service and as a consequence, it will be responsible for several lubricant related problems such as: increase in viscosity and acidification, additive depletion, and so on ${ }^{1}$. Therefore, controlling and monitoring oxidation level (and other related parameters) should be considered a priority in order to assure good machinery performance and reliability ${ }^{2}$.

In all lubricating systems and, perhaps even more, in internal combustion engines, organic compounds exposed to the presence of oxygen, high temperatures and pressures will partially oxidize into a large variety of by-products (react chemically with the oxygen), such as: ketones, esters, aldehydes, carbonates and carboxylic acids, that exhibit characteristic IR absorptions ${ }^{3-4}$. . It is this property that is utilized by the FT-IR Spectrometry to study the oxidation problems. The exact distribution and composition of these products is complex. Carboxylic acids contribute to the acidity of the engine oil and deplete its basic reserve as neutralization takes place. The net effect of prolonged oxidation is that chemically the oil becomes acidic causing corrosion, while a physical increase in viscosity occurs.

One of the most common methodologies used to measure oxidation level in used engine oils is the FT-IR spectrometry technique ${ }^{5}$. For many years it has been used to study lubricant degradation ${ }^{6-9}$ by measuring variations in the concentration profiles through the carbonyl $(\mathrm{C}=\mathrm{O})$ absorption region $\left(1,820 \mathrm{~cm}^{-1}-1,650 \mathrm{~cm}^{-1}\right){ }^{10}$. All of the by-products previously mentioned 
have highly characteristic vibration in this region: ketones $\left(1725 \mathrm{~cm}^{-1}\right.$ to $\left.1705 \mathrm{~cm}^{-1}\right)$, carboxylic acid $\left(1725 \mathrm{~cm}^{-1}\right.$ to $\left.1700 \mathrm{~cm}^{-1}\right)$, and ester $\left(1750 \mathrm{~cm}^{-1}-1725 \mathrm{~cm}^{-1}\right)^{11}$.

Despite this fact and the ASTM efforts to normalize oxidation measurements using this technique (ASTM E2412 and ASTM D7214) ${ }^{10,12}$, still nowadays there are a lot of commercial labs using their own internal procedures (usually variations based on the ASTM standard practices). This may cause problems when comparing and analyzing results from different labs because a slight change in the considered band length of the carbonyl region will affect the final result.

This work has been developed in order to propose a FT-IR methodology to monitor levels of oxidations and to analyze the effects of thermal degradation, base oil formulation and fuel dilution contamination on this variable, identifying two sub-zones ( $\mathrm{A}$ and $\mathrm{B}$ ) to be better quantified and monitored. As mentioned above, levels of oxidation by a general response in the carbonyl region. In this region, IR energy is absorbed due to the carbon oxygen bonds in the oxidized oil essentially present during the processes of thermal degradation, where product as carboxylic acid, ketones and aldehydes are in higher concentration, what was later identified as zone A. Short time ago with the incorporation of biofuels that has a very characteristic component as ester, come to cause significant change in this area when fuel dilution problems occurred, for that reason will be quantified in what is known as zone B.

This study has been performed using data obtained from real-world operating conditions and laboratory simulation tests. In real-world, to isolate different effects, different types of engines have been used, like: compressed natural gas (where the lubricant is expected to suffer high thermal stress and a slight or even none fuel dilution) and Diesel engines (where fuel dilution problems and low thermal stress condition ${ }^{1}$ are predominant). It is worth mentioning that specific type of engine oils will be used depending on the type of engine. In lab, it has been simulated, in an isolated way, thermal stress and fuel contamination.

\section{Overview of the infrared spectroscopy evolution and related methodologies}

FT-IR spectroscopy is used to track relative changes in used oil by subtracting the spectrum of the fresh oil from its used or in-service oil counterpart. In this way it can be spectrally visualized the molecular changes occurred and associated to typical lubricant problems such as: additive depletion, oxidation, nitration, soot content, fuel dilution, etc.

Next step was attempted to standardize the measurement of these changes in terms of absorbance or arbitrary units that can be correlated with machine faults or lubricant degradation level.

Perhaps, the most important effort in order to standardize the methodology and the analytical protocol was made by the US Armed Forces in the frame of the Joint Oil Analysis Program (JOAP) and summarized in a JOAP report ${ }^{13}$. In this report, several fundamental aspects related with FT-IR analytical condition monitoring protocol were presented such as: spectral regions and baselines based on standard additional experimentation for three oil categories: petroleum, synthetic (ester) and hydraulic oils. 
Further research lead to the development of an ASTM standard practice entitled ASTM E 2412 Standard Practice for Condition Monitoring of Used Lubricants by trend analysis using Fourier transform Infrared (FT-IR) spectrometry ${ }^{10}$.

In 2006 it was approved and published the standard ASTM D 7214 was approved and published in 2006: this test method covers the determination of the lubricants oxidation using the FT-IR technique ${ }^{12}$.

\section{Variables affecting oxidation measurements}

Temperature is undoubtedly one of the most important parameters affecting the oxidation process. Two related effects are governed by temperature; on one hand, the reaction activation energy, and on the other hand an effect over the speed of the reaction, with greater speed associated with higher temperature. This relationship is nonlinear, doubling the rate of oxidation for every $10^{\circ} \mathrm{C}$ increase in temperature ${ }^{14}$.

When lubricant oils are exposed to high temperatures in the presence of oxygen (air), oil begin to suffer a slow oxidation process in which the oil's hydrocarbons react with oxygen to form other substances, including organic acid derivatives, ketones, aldehydes as a main products, and ester in lower concentration. Engine oils are probably more susceptible to oxidation than in other lubricant applications, considering the high oil temperatures reached in the piston area and resulting in the called "thin film oxidation" ${ }^{15}$, causing that $\mathrm{CNG}$ oils have a higher degradation rate than in diesel engines, as it has been observed in previous studies ${ }^{1-2,16}$.

Oxidation effect due to oil temperature leads to important changes in the oil effectiveness as a lubricant such as: increasing the acidity of the oil ${ }^{17}$ and increasing the viscosity ${ }^{18}$, among other changes in properties. Consequently the lubricant becomes more aggressive toward metal surfaces, especially those non-ferrous, and modifies its ability to form a lubrication film, causing higher engine wear rate. For this reason a lot of analytical techniques (FT-IR, Potentiometric acid-base titrations, Voltammetry, Sealed capsule differential scanning calorimetry - SCDSC, gas chromatography - GC, etc.) have been used to try to quantify more precisely the products and effect of oil oxidation.

Fuel dilution problems have been long studied and different alternative measurement methods have been used to detect it such as: GC, flash point, fuel sniffer or viscosity excursions ${ }^{19-21}$. As evidenced, this is a problem that didn't influence the quantification of the oxidation levels by FTIT, due to the absence of products such as those found in biofuels which could present frequencies of vibration in this absorption region $\left(1,820 \mathrm{~cm}^{-1}-1,650 \mathrm{~cm}^{-1}\right)$.

Automotive fuels can consist of a wide variety of branched aliphatic compounds, aromatic compounds, and many other compounds blended to produce a desired set of physical properties. The typical conventional fuels dilution problems, such as gasoline and diesel ${ }^{10}$ can be identified mainly in the spectral range between $815 \mathrm{~cm}^{-1}$ and $745 \mathrm{~cm}^{-1}$. This absorbance band is typical for out-of-plane bending of two adjacent hydrogens in a para-substituted aromatic ring that have highly characteristic vibration in this region. If low aromatic is analyzed, FT-IR won't tell anything and is very complicated to determinate the presence of fuel dilution. As can be seen, this range is quite far from the range associated to oxidation measurements thus avoiding 
interference problems that will not affect the quantification of the levels of oxidation. But this situation is changing due to the introduction and use of biofuels (according to European regulation allowed up to 7\% v/v content of biofuels - UNE EN 590), and especially in diesel engines where biodiesel blends are being used in this case, the biodiesel constituents (methyl esters from vegetable oils) present big spectral interference in the oxidation quantification area (Approximately at 1,745 cm-1) when applying FT-IR. Additionally, this problem becomes worse associated with higher biodiesel blends.

FT-IR measurements also can be a powerful method for detecting fuel dilution when the amount of biodiesel blended into diesel fuel increases.

\section{Characteristic of methodology and Samples}

\section{Methodology measurement}

Taking into account the standard procedure previously presented and type of machine to be monitored (internal combustion engines), it was developed a specific methodology, mainly based on the previously presented ASTM D7214 and ASTM E 2412, using a FT-IR device by A2 Equipment Technologies. This equipment has the following main characteristics:

Table 1: Main FTIR equipment characteristic

\begin{tabular}{|lc}
\multicolumn{2}{c}{ Characteristics } \\
\hline Spectral range & $4,700 \mathrm{~cm}^{-1}$ to $590 \mathrm{~cm}^{-1}$ \\
\hline Resolution & $4 \mathrm{~cm}^{-1}$ \\
\hline Sample scan & 128 \\
\hline Background scan & 128 \\
\hline Path length mm (micron) & $0.1(100)$ \\
\hline Sampling cell material & Zinc Selenide (ZnSe) \\
\hline Interface & Transmission- TumbIIR \\
\hline Apodization & Triangular
\end{tabular}

The measurements of the oxidation levels were performed in the range between $1,770 \mathrm{~cm}^{-1}$ and $1,650 \mathrm{~cm}^{-1}$ and reported as peak area increase (PAI, units: Abs $\mathrm{cm}^{-1} / \mathrm{mm}$ ), following ASTM D 7214, or peak high (PH, units: Abs) as a conventional quantification, for all analyzed samples. For this paper, the Path length was $0.1 \mathrm{~mm}$ (100 micron) and were performed using a single baseline starting at $1,850 \mathrm{~cm}^{-1}$ and ending at $1,620 \mathrm{~cm}^{-1}$.

\section{Samples characteristic}

To perform this study, different types of samples have been used. On one hand, there have been samples obtained from engines under real working conditions in an urban transport fleet. On the other hand, samples were specifically. 
Table 2: Fresh oils main characteristics

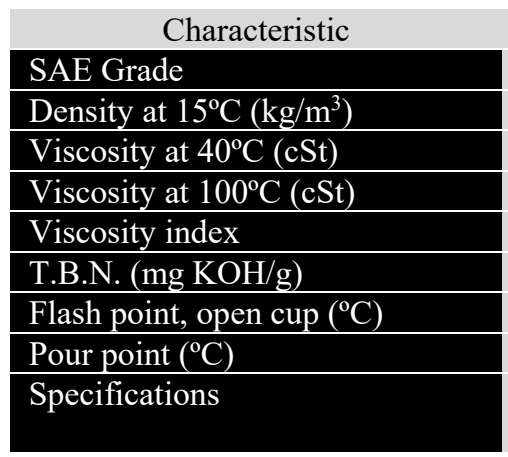

$\begin{array}{cccc}\text { Oil Type A } & \text { Oil Type B } & \text { Oil Type C } & \text { Oil Type D } \\ 15 \mathrm{~W} / 40 & 10 \mathrm{~W} 40 & 15 \mathrm{~W} / 40 & 5 \mathrm{~W} 50 \\ 885 & 865 & 881 & 859 \\ 112.0 & 91.8 & 108.0 & 105 \\ 14.5 & 14.3 & 14.5 & 17.3 \\ 125 \mathrm{~min} . & 160 & 130 \mathrm{~min} . & 153 \\ 10 & 13.2 & 10 & 9.0 \\ 215 & >220 & 215 \mathrm{~min} . & 236 \\ -27 & <-33 & -27 \mathrm{max} & -51 \\ \text { API CF-4 } & \text { IVECO } 18- & \text { API CI- } & \text { API } \\ & 1809 & 4 / \mathrm{CH}-4 / \mathrm{SL} & \text { SM,SL,CF }\end{array}$

Vehicles tested on the urban fleet are powered by two different types of engines: diesel and CNG fuelled engines. Main characteristics of each type of engines are presented on Table 3. For CNG engines, two types of engine oil have been used, the first one (named oil A) is a 15W40 mineral oil and second one (oil B) is a 10W40 synthetic oil with higher anti-oxidant additive package, all of this in order to check oils performance in similar working conditions. Diesel engines are lubricated with oil type C, a 15W40 mineral oil.

Additional synthetic engine oil 5W50 (named oil D), base oil API group IV, will be used for lab test. The main characteristics of all the fresh oil employed in the present study are summarized on Table 2.

Table 3: Engines main characteristics

\begin{tabular}{|lcc|}
\multicolumn{1}{c}{ Characteristics } & CNG vehicle type & Diesel vehicle type \\
\hline Type & II / TC & DI / TC \\
\hline Number of Cylinder & 6 & 6 \\
\hline Bore / stroke (mm) & $115 / 125$ & $128 / 155$ \\
\hline Engine displacement (cc) & 7,790 & 11,967 \\
\hline Power (kW) & $200 @ 2,000 \mathrm{rpm}$ & $220 @ 1,900 \mathrm{rpm}$ \\
\hline bmep (bar) & 15.4 & 11.6 \\
\hline Power/displacement (kW/1) & 25.67 & 18.38 \\
\hline Oil drain period (km) Engine & 15,000 & 35,000 \\
manufacturer recommendation & & \\
\hline Oil sump capacity (1) & 23 & 31 \\
\hline Oil type in use & Oil A and B & Oil C
\end{tabular}

II: Indirect Injection - DI: Direct Injection - TC: Turbocharged

Vehicles samples were taken for used oil analysis each 5,000 km. Additional samples were also taken at the end of the oil drain period for each type of engine, being $15,000 \mathrm{~km}$ for CNG engines and $30,000 \mathrm{~km}$ for diesel engines according to the operator policy attending previous used oil analysis. Vehicles have frequent stop and go service, large periods of engine idling and average speed of $12.7 \mathrm{~km} / \mathrm{h}$. Vehicles are equipped with automatic fresh oil refilling systems. 
A second group of samples studied have been evaluated in the laboratory, after a specific degradation process and coming from the same types of fresh oils previously presented (A, B, C and D).

Two degradation processes have been considered; first one, representing thermal degradation, has been simulated using a thermal bath at $270^{\circ} \mathrm{C}$ during 48 hours. To avoid possible external factors affecting degradation such as the catalysis effect of metal components, this process was performed in a glass beaker and samples were collected every six hours. Temperature selected for the thermal bath was higher than those in other standard oxidation tests ${ }^{15,22-24}$ with the purpose of simulating strong thermal oxidation, similar to those situations where engine oils can rise to over $250-260^{\circ} \mathrm{C}$ in real operation, due to hot spots in the engine in contact with the lubricant, as in the first piston groove near the combustion chamber ${ }^{25}$.

To assess the effects of fuel contamination, those oils specifically formulated for Diesel engines (types C \& D) were diluted at different degrees $(1,3,5,7,10,15$ and 20\%), using different biodiesel fuel blends: B10 and B20.

\section{Results}

\section{Samples from engines in real service}

Figures 1 and Figure 2 shows the results for $\mathrm{CNG}$ engines samples in real operating conditions in a transport fleet.

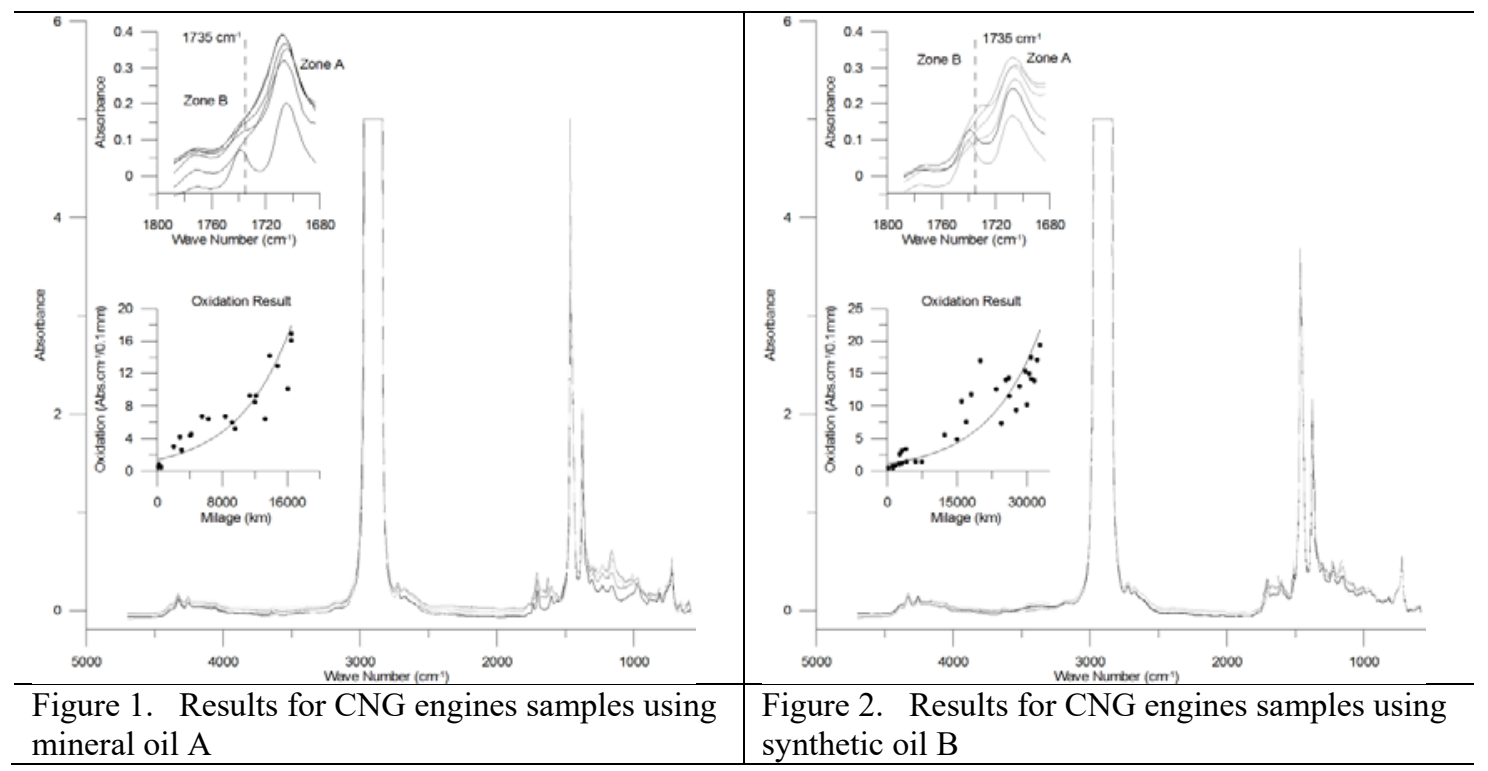

In Figure 1, it can be observed the complete FT-IR spectra for the five most representative samples from $\mathrm{CNG}$ engines using oil A, including the fresh oil sample, which is depicted with a dark color. The lower left hand side graph of figure 1 represents the extreme values computed in absorbance values and measured as a PH (Peak High). As can be seen on the upper zoom range between $1,780 \mathrm{~cm}^{-1}$ and $1,680 \mathrm{~cm}^{-1}$, fresh oil have absorbance values around $0.2 \mathrm{Abs}$ in zone $\mathrm{A}$, while samples representing maximum oil degradation reach values up to $0.4 \mathrm{Abs}$. 
It can also be observed, that the initial peak present in the zone B associated to fresh oil, gradually disappears in used oil samples as a direct consequence of oil degradation related to thermal stress.

Bottom left area of Figure 1 present the results of oxidation quantification using PAI (Peak Area Increase) method for all 30 samples pertaining to this group. Maximum values of $18 \mathrm{Abs}^{\cdot} \mathrm{cm}^{-}$ $1 / 0.1 \mathrm{~mm}$ have been reached at the end of oil drain period, around $16,000 \mathrm{~km}$. A direct relation between oil degradation (oxidation) and oil mileage ${ }^{1}$ can be observed.

Figure 2 main graph shows FT-IR spectra for those five most samples considered representative out of the full group (30 samples), corresponding to CNG engines lubricated with synthetic oil B. As can be seen, the behavior is quite similar to the previous case. As can be seen on the upper zoom range between $1,780 \mathrm{~cm}^{-1}$ and $1,680 \mathrm{~cm}^{-1}$, fresh oil presents absorbance values slightly lower than $0.2 \mathrm{Abs}$ in zone $\mathrm{A}$, while samples representing maximum oil degradation reach values around $0.35 \mathrm{Abs}$. It is worth noting that for this case oil mileage is substantially higher than before, reaching more than $30,000 \mathrm{~km}$. This situation can be mainly caused by the use of improved antioxidant additive packages and base oil. Bottom left area of Figure 2 presents the results for oxidation quantification using the PAI (Peak Area Increase) method for this samples and it can be seen that values have been $21 \mathrm{Abs}^{\cdot} \mathrm{cm}^{-1} / 0.1 \mathrm{~mm}$ at the oil drain period.

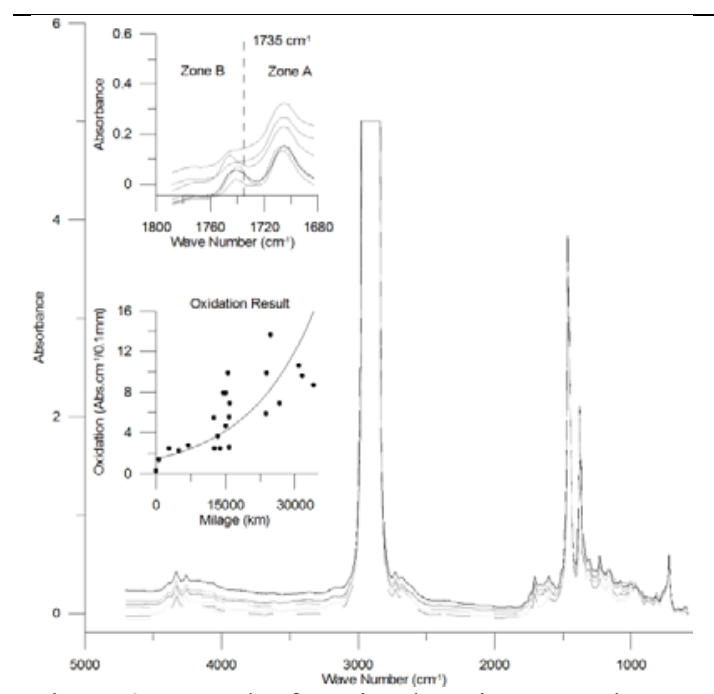

Figure 3. Results for Diesel engines samples using mineral oil C

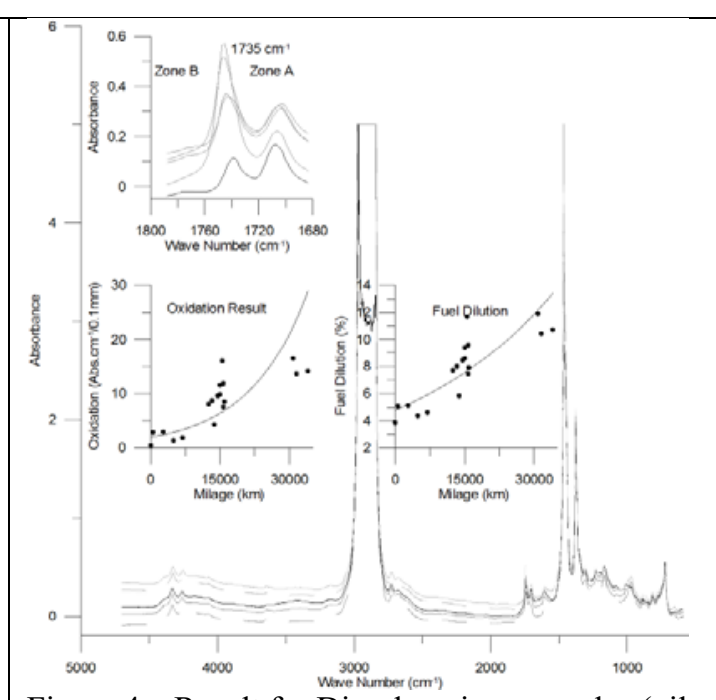

Figure 4. Result for Diesel engines samples (oil C) with fuel dilution problems

Figure 3 represents the evolution of the oxidation level of a mineral oil (type C) samples from Diesel engines. Similar behavior can be observed with previous result, but with lower oxidation values (Peak Area Increase measurement) about $12 \mathrm{Abs}^{\cdot} \mathrm{cm}^{-1} / 0.1 \mathrm{~mm}$. This situation can be considered as a direct result of a lower thermal stress suffered by engine oil in Diesel engines. Additionally, it can also be assumed that a certain reduction effect is associated to a lower value of peak high for fresh oil C compared with oils A or B. 
In all these cases, the trend of the spectra of lubricating oils is the growth of the zone A, both in terms of $\mathrm{pH}$ and $\mathrm{PAI}$, as a direct result of thermal degradation suffered by engine solicitation. Also is seen mostly lower zone B.

As it has been detected in samples coming from engines in real service, oxidation levels reached in oil B are lower than those obtained in oil $\mathrm{A}$ as a result of its better base oil and higher additive package.

Figure 4 presents the results for those samples coming from specific Diesel vehicles that have fuel dilution problem. The fuel was B20 biodiesel blend. As can be observed, fuel dilution problems can be easily detected showing the important peak increase reaching values about 0.6 $\mathrm{Abs}$, in Zone B $\left(1,770 \mathrm{~cm}^{-1}\right.$ to $\left.1,735 \mathrm{~cm}^{-1}\right)$.

To quantify the fuel dilution percentage presented on Figure 4, the following equation has been used:

$$
\text { Fuel Dilution }(\%)=0.4984 \cdot P H+3.6607
$$

This equation was obtained as a calibration curve in laboratory tests using fresh oil and B20 biodiesel blend.

In this case, the sample had a higher fuel contamination came to get values up to $20 \% \mathrm{v} / \mathrm{v}$, which shows a clear effect in Zone B, up to obtain values well above the thermal degradation in Terms of PH.

\section{Samples from lab degradation tests}

Next figures, from Figure 5 to Figure 8, present the results for lab thermal degradation tests for the different types of engines oils considered.

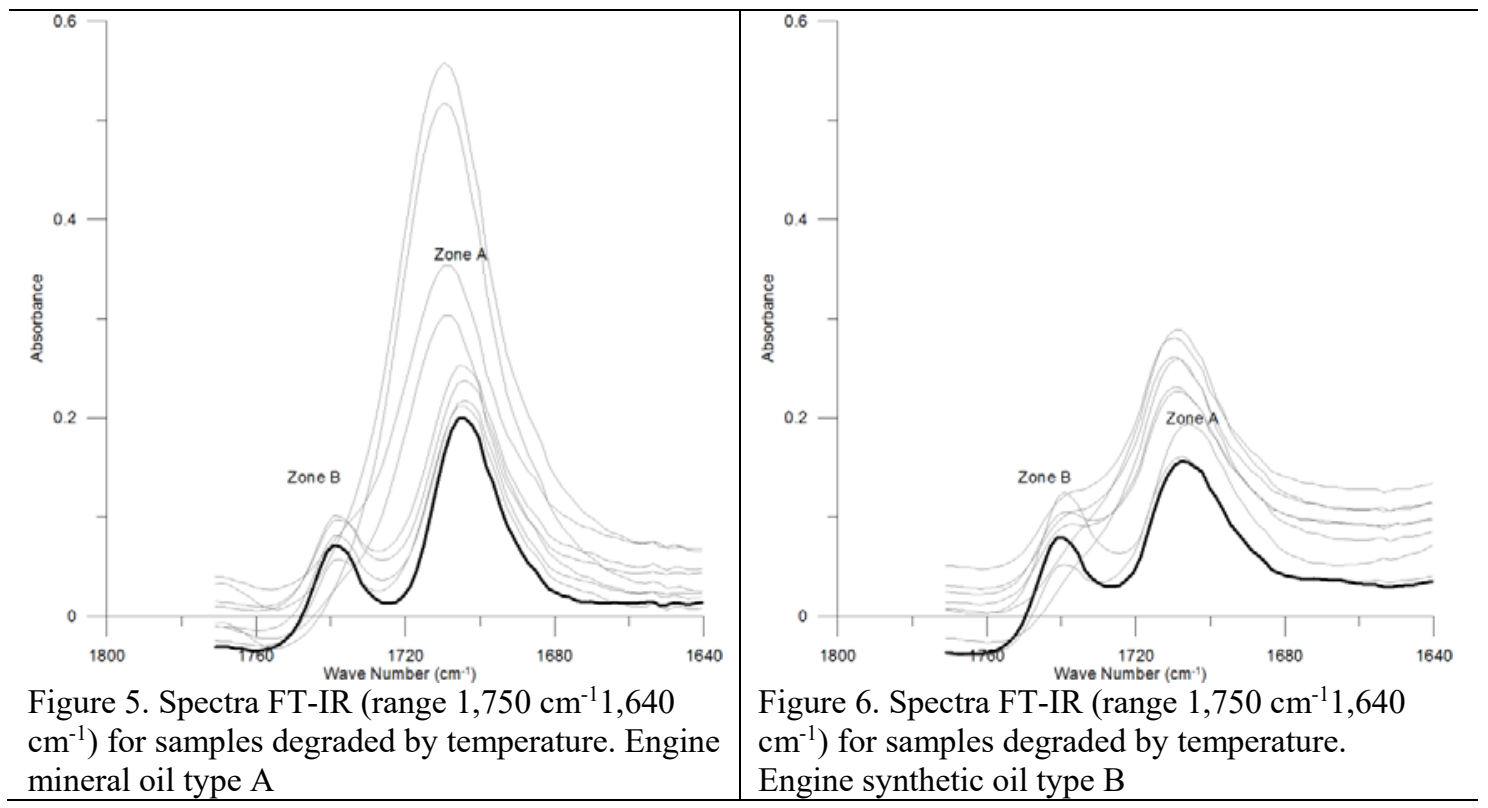




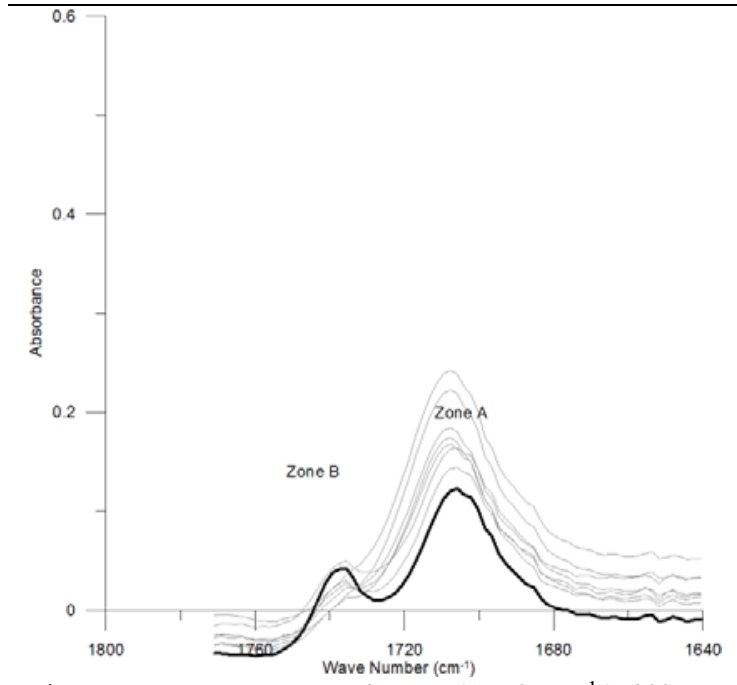

Figure 7. Spectra FT-IR (range 1,750 $\mathrm{cm}^{-1} 1,640$ $\mathrm{cm}^{-1}$ ) for samples degraded by temperature. Engine mineral oil type C

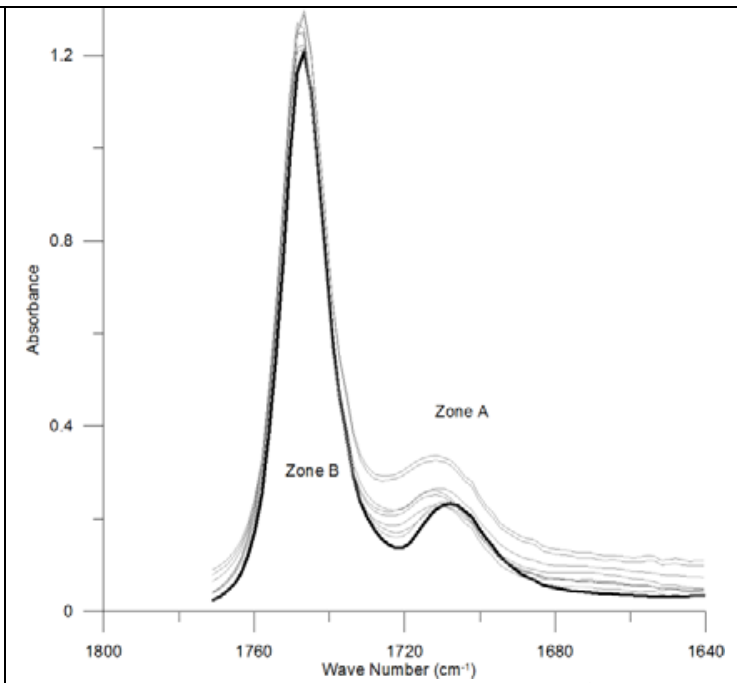

Figure 8. Spectra FT-IR (range $1,750 \mathrm{~cm}^{-1} 1,640$ $\mathrm{cm}^{-1}$ ) for samples degraded by temperature. Engine synthetic oil type D

As can be observed, the thermal degradation is mainly characterized by a peak increase in Zone A $\left(1,725 \mathrm{~cm}^{-1}-1,650 \mathrm{~cm}^{-1}\right)$. There is a clear difference between oil D (Fig. 8), formulated using a API IV base oil, and the other types of engine oils considered. The same behavior observed in samples from engines in real service, related with the peak present in Zone B and associated to fresh oil, gradually disappears in degraded samples is observed on these simulation tests. The peak referred before has absolutely disappeared in most of the degraded samples, as can be observed through Figures 5 to 7.

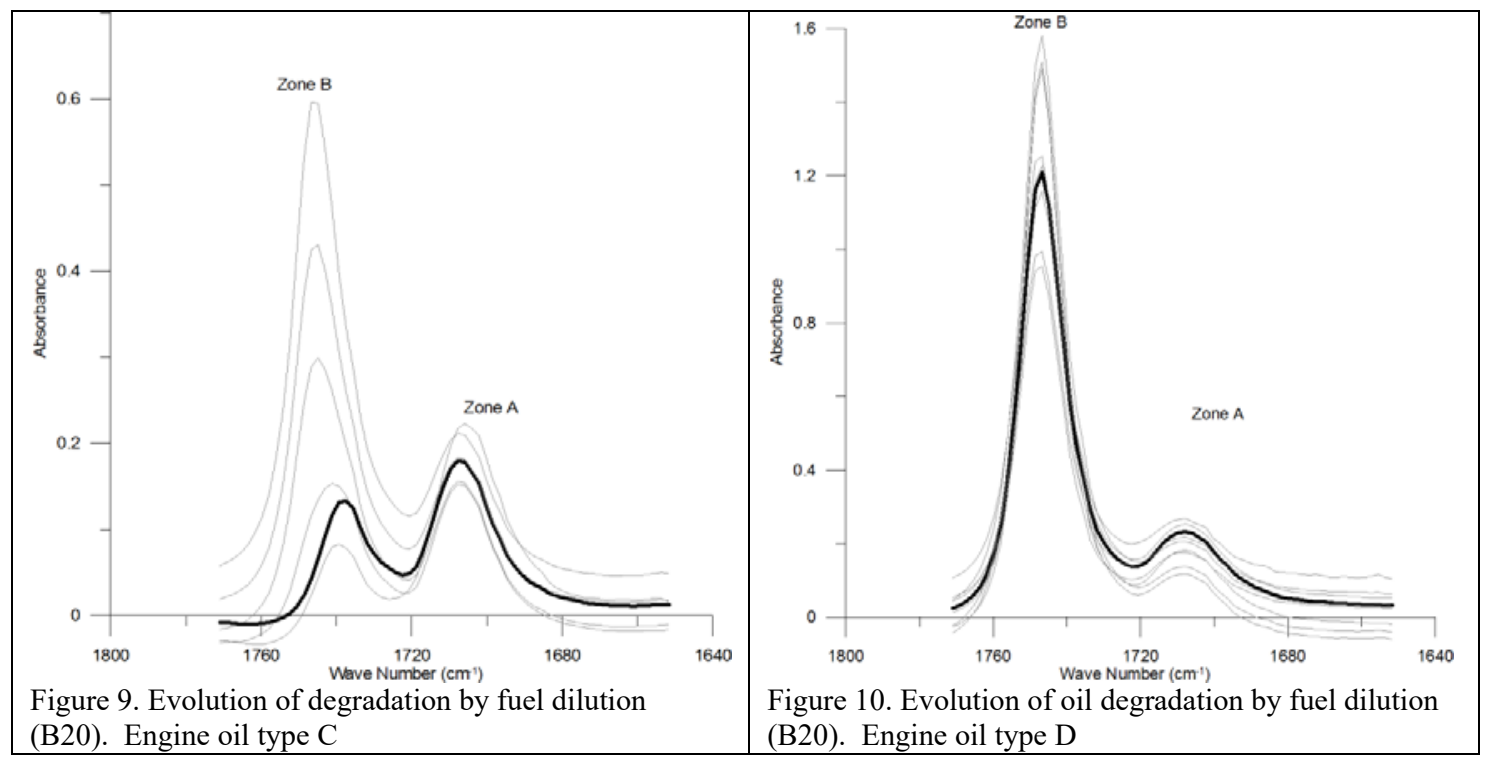

Figure 9 and Figure 10 show the results for lab fuel contamination test. As can be observed, fuel dilution effect is mainly reflected as a peak spectra increase in Zone $B\left(1,770 \mathrm{~cm}^{-1}-1,725 \mathrm{~cm}^{-1}\right)$. The oil D has a special behavior because the high absorbance in Zone B (1.4 Abs) related with 
its synthetic origin (ester base oil), leads to difficulties in the detection of changes associated to fuel contamination. In most cases there is a decrease of absorbance in this area (Fig. 10). In an uncommon scenario, where B20 biodiesel blend are used and high fuel dilution problems are present, is possible to see a slightly increase in absorbance values (Fig. 10). Oil C (degraded in the lab) has the same behavior observed in samples from engines in real service and related with the peak located in Zone B and associated to fresh oil; this peak increases gradually in contaminated samples (up to $0.6 \mathrm{Abs}$ measured as a Peak High with $20 \%$ of fuel dilution using a B20 blend, Fig. 9).

\section{Conclusions}

A particular procedure, based on ASTM D7214, has been defined to improve oxidation quantification and problem detection in internal combustion engine used oils. Two parameters have been used depending on potential problems that can be present on samples: Peak High (PH) and Peak Area Increase (PAI). The wave number range considered has been between $1,770 \mathrm{~cm}^{-1}$ and $1,650 \mathrm{~cm}^{-1}$ using a single baseline from $1,850 \mathrm{~cm}^{-1}$ to $1,620 \mathrm{~cm}^{-1}$. Inside the main wave number range, two zones have been defined; taking into account where the studied variables (Thermal degradation and fuel dilution) could be more easily detected in each one. Zone $\mathrm{A}$ has been defined between $1,725 \mathrm{~cm}^{-1}$ to $1,650 \mathrm{~cm}^{-1}$ and zone $\mathrm{B}$ has been defined between $1,770 \mathrm{~cm}^{-1}$ to $1,725 \mathrm{~cm}^{-1}$.

Oil degradation related with thermal stress shall be mainly studied in the range of $1,725 \mathrm{~cm}^{-1}$ $1,650 \mathrm{~cm}^{-1}$, because as it has been observed in this work, this is the range where most of the byproducts of the thermal oxidation degradation process present higher absorbance values.

Carboxylic acids and Ketone are the main products, where the $\mathrm{C}-\mathrm{O}$ and $\mathrm{O}-\mathrm{H}$ vibrations are highly characteristic in this frequency range.

Fuel contamination detection could be performed in additional wave number ranges that those offered by the ASTM standard practice $\left(835 \mathrm{~cm}^{-1}\right.$ to $\left.735 \mathrm{~cm}^{-1}\right)$. Taking into account the increase of biofuels blends, used to fuel diesel engine, these problems are much easier to be identify in previously defined zone $\mathrm{B}\left(1,775 \mathrm{~cm}^{-1}-1,725 \mathrm{~cm}^{-1}\right)$. In different products that contain ester $\left(1,750 \mathrm{~cm}^{-1}-1,725 \mathrm{~cm}^{-1}\right)$ from the biofuel, have vibrations highly characteristic in this frequency range. This procedure presents more advantages when higher biodiesel blends are used.

\section{Acknowledgements}

The authors wish to thank to Spanish Grant TRA2008-06508 (GLAUTO) from Ministerio de Ciencia e Innovación - Dirección General de Investigación for supporting this work. 


\section{References}

[1] Macián, V., Tormos, B., Salavert, J.M. and Gómez, Y.A. (2010), “Comparative Study of Engine Oil Performance on CNG/Diesel Engines on an Urban Transport Fleet". SAE Paper 2010-01-2100, DOI: 10.4271/2010-01-2100.

[2] Macián, V., Tormos, B., Redón, P. and Ballester, S. (2008), "Behavioural study of engine oil lubricants in gas engines used in urban transport fleets". Lubrication, Maintenance and Tribotechnology.

[3] Rudnick, L. (2003), “Lubricant Additives - Chemistry and Applications”. CRC Press Taylor \& Francis Group, ISBN-13: 978-0824708573.

[4] Maleville, X., Faure, D., Legros, A. and Hipeaux, J.C. (1996), "Oxidation of Mineral Base Oils of Petroleum Origin: The Relationship between Chemical Composition, Thickening, and Composition of Degradation Products". Lubricant Science. 9, pp. 3-60.

[5] Van de Voort, F. R., Sedman, J., Cocciardi, R.A. and Pinchuck, D. (2006), "FT-IR Condition Monitoring of In-Service Lubricants: Ongoing Developments and Future Perspectives" Tribology Transactions. 49, Issue 3, pp. 410-418

[6] Coates, J. and Setti, L. (2008), "Infrared Spectroscopic Methods for the Study of Lubricant Oxidation Products". ASLE Transactions. 29, Issue 3, pp. 394-401

[7] Powell, J.R. and Compton, D.A. (1993), “Automated FT-IR Spectrometry for Monitoring Hydrocarbon-Based Engine Oils”. Lubrication Engineering. 49, pp. 233-239.

[8] Van de Voort, F.R., Ismail, A.A., Sedman, J. and Emo, G. (1994), "Monitoring the Oxidation of Edible Oils by Fourier Transform Infrared Spectroscopy". Journal of the American Oil Chemists' Society. 3, pp. 243-253.

[9] Van De Voort, F.R., Sedman, J., Cocciardi, R.A. and Pinchuk, D. (2006), "FT-IR Condition Monitoring of In-service lubricants: Ongoing Developments and Future Perspectives".

Tribology Transactions. 49, pp. 410-418.

[10] E2412-04 (2004), "Standard Practice for Condition Monitoring of Used Lubricants by Trend Analysis Using Fourier Transform Infrared (FT-IR) Spectrometry”. ASTM International, West Conshohocken, PA.

[11] Coates, J. (2000), "Interpretation of infrared spectra, a practical approach. Encyclopedia of Analytical Chemistry”, John Wiley \& Sons Ltd, Chichester, pp. 10815-10837.

[12] D7214-07 (2007), "Standard Test Method for Determination of the Oxidation of Used Lubricants by FT-IR Using Peak Area Increase Calculation. ASTM International, West Conshohocken, PA. 
[13] Toms, A. (1994), "Fourier transform infrared (FT-IR) Final Report Technical Support Center”, Joint Oil Analysis Program, Pensacola, JOAP-TSC-95-01 Bio-Rad FTS7.

[14] Wooton, D. (2007), “The lubricant's nemesis - oxidation. Practicing Oil Analysis"

[15] Adamczewska, J.Z. and Love, C. (2005), "Oxidative Stability of Lubricant Measured by PDSC CEC L-85-T-99 Test Procedure”, Journal of Thermal Analysis and Calorimetry. 80, pp. $753-759$

[16] Semin, A.R. and Rosli, A.B. (2009), "Combustion Temperature Effect of Diesel Engine Convert to Compressed Natural Gas Engine", American Journal of Engineering and Applied Sciences. 2, pp. 212-216.

[17]. Oliveira, J.C., Garcia, I.M., Gouveia, A., Sobrinhoc, E.V., Fernandes, V.J. and Silvaa, A.J. (2004), "Thermoanalytical and Rheological Characterization of Automotive Mineral Lubricants after Thermal Degradation". FUEL - The Science and Technology of Fuel and Energy. pp, 23932399

[18] Owranga, F., Mattsson, H., Olsson, J. and Pedersen, J. (2004), "Investigation of Oxidation of a Mineral and a Synthetic Engine Oil”, Thermochimica Acta. 413, pp. 241-248

[19] Hiltz, J.A., Veino, D.E. and Haggett, R.D. (1989), “A study of fuel dilution of diesel lubricating oil by gas chromatography/mass spectrometry", Technical Memorandum.

[20] Tormos, B. (2002), "Contribución al diagnóstico de motores diesel en basado en el análisis del lubricante usado". Universidad Politécnica de Valencia, I.U. Máquinas y Motores Térmicos CMT, Valencia, Spain.

[21] Mortier, R., Fox, M.M. and Orszulik, S.T. (2010), "Chemistry and Technology of Lubricants”, ISBN 978-1-4020-8661-8.

[22] Bowman, W.F. and Stachowiak, G.W. (1996), "Determining the Oxidation Stability of Lubricating Oils Using Sealed Capsule Differential Scanning Calorimetry (SCDSC)", Tribology International, 29, pp. 27-34.

[23] Cerny, J., Strnad, Z. and Sebor, G. (2001), "Composition and oxidation stability of SAE 15W-40 engine oils”, Tribology International, 34, pp. 127-134.

[24] Moehle, W.E., Cobb, T.W., Schneller, E.R. and Gatto, V. (2007), Utilizing the TEOST MHT® to Evaluate Fundamental Oxidation Processes in Low-Phosphorus Engine Oils.

Tribology Transactions. 50, Issue 1, pp.96-103

[25] Maleville, X., Faure, D., Legros, A. and Hipeaux, J.C. (1996), "Oxidation of mineral base oils of petroleum origin: The relationship between chemical composition, thickening, and composition of degradation products". Lubrication Science, DOI: 10.1002/1s.3010090102. 